\title{
Allergic evaluation of Roystonea regia (Kunth.) O. F. Cook. among Keralites, India.
}

Sushama Raj R. V.* and Prakshkumar R.

Department of Botany, Mahatma Gandhi College, Thiruvananthapuram, Kerala, India.

Received: 12/24/2017; Revised: 1/11/2018; Accepted: 1/25/2018

\begin{abstract}
Aerobiological studies conducted in Kerala (India), revealed the incidence of pollen grains of Roystonea regia (Kunth.) O.F.Cook. belonging to the family Aracaceae as a common airborne pollen member. Previous clinical studies conducted in different parts of the world also proved its allergic potentiality among human beings. Present study concerned with the clinical studies of this particular airborne pollen type among Keralites. Intradermal skin test results of 1000 patients having the history of respiratory complaints was collected for the allergy evaluation study. Results showed that this particular pollen type is highly potent allergen and the degree of reactivity is depends the locality in which the patients inhabits.
\end{abstract}

Keywords: Allergy, Intradermal skin test, pollen grains

\section{Introduction}

Nasobronchial allergy and associated illness are considered to be the most ancient but relevant health diseases of human beings. The term "allergy" was first introduced by a Viennese pediatrician Clemens Von Pirquet. He defined it as an acquired, specific and altered capacity to react vigorously to re-exposure to a viable or non-viable agent. Materials that are capable of trigger allergic reactions are referred as allergens and are most commonly airborne. Such types of airborne allergens are commonly called as "aeroallergens".

Nature of aeroallergens varies from place to place depending upon the environmental, climatic and other geographical conditions. Majority of allergic manifestations may happen due to the inhalation of particles like reproductive spores of plants and fungi. In Canada and United States, the commonest cause of nasobronchial allergy is the Rag weed pollen. Among grasses, Timoty and June grasses are the important group. In Sweden, tree pollen allergens are responsible for hay fever reactions.

Kerala, Southernmost state of India, is characterized for its diversity in flora and fauna. Despite this diversity little study is conducted which involve the characterization of different pollen types present in the environment. Aerobiological studies conducted at the Department of Respiratory Medicine during late eighties and early nineties, revealed the presence of large number of pollen grains in the atmosphere. Clinical studies proved that, about $70-80 \%$ of them are potent allergens (Ravindran et al., 1986, 1988; Nair et al, 1986, Gopi et al, 1992 and Prakashkumar, 1989, 1993). These became the foundation for the present study. Among them a large number of

\section{*Corresponding Author:}

Dr. Susahma Raj R. V.

Asst. Prof. \& Head, Department of Botany,

H.H.M.S.P.B. N.S.S. College for Women, Neeramankara,

Thiruvananthapuram, Kerala, India.

E-mail: drsushamarajrv@gmail.com pollen samples belong to the family Poaceae and Arecaceae were identified.

The present work concerns the antigenic extraction and allergy evaluation by intradermal skin testing of the pollen grain types of Roystonea regia (Kunth.) O.F.Cook. Analysis of allergenic response among a sample of 1500 patients who reported at the allergy and Applied Immunology clinic of the Department of Respiratory Medicine, Medical College, Thiruvananthapuram. It is expected that the study bring forth results relevant to the signal areas of diagnosis and clinical management of allergic reactions due to this pollen type.

\section{Materials and Methods}

\section{Materials}

Of the innumerable species of plants whose pollen grains are allergenic, only those which are wind pollinated are clinically significant. In order to cause the disease, such plants should be abundant in the environment and also must produce large quantities of pollen grains. Considering the above facts, pollen grains of Roystonea regia (Kunth.) O.F.Cook. belonging to the family Arecaceae was selected for the present study.

This is a robust tree popularly known as "Royal Palm", indigenous to Central America and shows wide distribution in India. This species is popularly known under the synonyms, Oreodoxa regia, Kunth. and Palma elata, W. Bartram. This is one of the finest and grandest pinnate palms, which grows to a height of over 20 meters. It bears numerous feathery leaves on the solitary and spineless erect trunk which is swollen at the middle. The leaves are 
terminal, pinnate and $2-3 \mathrm{~m}$ long. The leaflets are $0.8 \mathrm{~m}$ long and unequally bifid at the tip. The spadix is large with long, slender and pendent branches. Two spathes (protective cover seen associated with inflorescence) are present with a lower broad, lateraly carnate which is shorter than the spadix and upper semi-cylindrical and complete. The bracts and bracteoles are scaly. The flowers are small, white and unisexual. The fruits are ovoid or obliquelyovate. The seeds are small, obovate and somewhat curved with sub based embryo

Fresh inflorescence (spadix) of Roystonea regia were collected in triplets from five different localities of the Highlands, Midlands and Coastalbelt of Kerala State. From the Spadix, pollen grains were collected in bulk for further investigations.

\section{Collection, Purification, drying and defatting of pollen grains}

The pollen were collected in bulk, air dried and sieved to remove the debri. Collected pollen grains were passed through 100, 200 and 300 mesh sieves. Purity was confirmed by observing through a microscope, with $99 \%$ pure being considered as Agrade pollen. Proper dehydration was done by keeping the pollen grains in a hot air oven at $60^{\circ} \mathrm{C}$ for one to three hours, which prevents microbial contamination. Purified pollen grains were defatted in Petroleum ether, which was later filtered, evaporated and dried. These steps were repeated thrice until defatting of pollen grains is completed.

\section{Antigen extraction.}

Antigenic extraction of these pollen grains were made in Phosphate Buffered Saline of $\mathrm{pH} 8.0$ following Sheldon et al. (1967). Known amount of pollen grain was put in PBS, mixed thoroughly and the extraction was done for 72 hours at $4^{\circ} \mathrm{C}$. After extraction, the extract was filtered and clarified by passing through millipore filters of pore size 0.45 $\mathrm{mm}$ attached to Sartorius filter adaptors (Sartorius, Germany.). For lyophylisation, the clarified products were dialyzed using dialysis tubes of $27 \times 32$ " tubings, for 24 hours. Lyophylised products were constituted later as 1:500 w/v for clinical. The extracts were sterilized using proper reagents. The aerobic and anaerobic sterility testing using Soyabean Casein Digest medium (Himedia Lab, India.) and Brewer Thioglycolate medium (Difo laboratories, Detroit, Michgan, USA) was done after filtering the extracts through millipore filters of 0.22 $\mathrm{mm}$.

\section{Allergy Evaluation Sample selection}

A total of 1500 patients were selected from those attending the Department of Respiratory Medicine, Medical College, Thiruvananthapuram, Kerala, due to allergic complaints. The patients were selected by definite inclusion - exclusion criteria. Patients of age between 10-49 years and a history of respiratory allergy were included. Patients of chronic asthma for 10 years or more, patients below 10 and above 49 years and patients on daily steroids were excluded. Also those having associated illness like food allergy, drug allergy and other associated problems were excluded from the study.

\section{Intradermal skin test (ID)}

Allergy evaluation was done based on the procedure of Chai et al. (1975). The patient is seated comfortably, cleaned with $70 \%$ alcohol and allowed to dry evaporation. The upper half of the volar surface of the fore arm was selected as the test sites and were marked leaving sufficient space. 1:500 dilution of antigenic extract was used for testing. Phosphate Buffered Saline (PBS) and histamine phosphate $(100 \mu \mathrm{g} / \mathrm{ml})$ were used as negative and positive controls respectively.

Sterile $1 \mathrm{ml}$ glass tuberculine syringe with 26 gauge needle were filled with $0.1 \mathrm{ml}$ of the test solution. All the air bubbles were expelled fully to eliminate misleading splash reactions which could be interpreted mistakenly as abnormal. Stretched the skin and the syringe was placed an angle of $45^{\circ}$ to the arm, introducing the needle into the skin. Advanced the needle until the entire level of the needle was into the skin penetrating entirely, but not going deeper than the superficial layers of the skin, since subcutaneous injections can lead to a false negative test. Injected gently a small amount of allergen solution that can raise a bleb of 1-3 mm diameter (approximately $0.02 \mathrm{ml}$ of solution). But if no wheal is formed immediately after injection, the needle was withdrawn and repeated the test at a different site. The skin reactions were read after 15 to 20 minutes. The degree of reactivity was calculated by measuring the wheel size after 20 minutes and interpreted based on Chai et al. (1975) (Table 01). The size of wheal was measured with a reaction gauge. The pseudopods, erythema (if occurs) were also noted.

\section{Results and Discussion}

Respiratory ailments due to the inhalation of various foreign substances is a serious concern among people across the globe. These substances are usually present in the surrounding environment of the susceptible individual. Such agents irrespective of its nature-being biotic or abiotic seriously affect the individuals when it comes in contact with the organ system. There are many forms of allergic manifestations among which allergic rhinitis and bronchial asthma are important.It has been well established that allergic problems are often caused by the inhalation of various substances. Among the biotic factors, reproductive spores of various plant organisms hold a major role to play. Studies conducted during these years have shown that many pollen types 
are potentially allergic in various degrees (Shivpuri and Singh, 1971; Cvitanovic et al, 1986; Tiwari, 1978; Agashe and Anand, 1982; Meyers et al, 1986). Intensity of hypersensitivity reactions can be determined by various diagnostic tools, among which intradermal skin testing is considered to be the most relevant and accepted procedure.

The incidence to the skin test response to Roystonea regia (Kunth.) O.F.Cook. antigen among the patients is presented in table 02. Among the 1500 patients subjected to intradermal skin test with the pollen antigen of Roystonea regia, 953 patients $(63.53 \%)$ reacted positively. Among this a group of 734 patients $(48.93 \%)$ showed significant reactivity in the skin test (Table: 02 ) (Fig: 01).

Table 1. Criteria to read Intradermal Test

\begin{tabular}{cccccc}
\hline $\begin{array}{c}\text { Control } \\
(\mathbf{m m})\end{array}$ & $\mathbf{\pm}$ & $\mathbf{1 +}$ & $\mathbf{2 +}$ & $\mathbf{3 +}$ & 4+ $\boldsymbol{\&}$ above \\
\hline 2 & $3-4$ & $5-7$ & $8-10$ & $11-14$ & Above 14 \\
3 & $4-5$ & $6-8$ & $9-11$ & $12-45$ & Above 15 \\
4 & $5-6$ & $7-9$ & $10-12$ & $13-16$ & Above 16 \\
5 & $6-7$ & $8-10$ & $11-13$ & $14-17$ & Above 17 \\
6 & $7-8$ & $9-11$ & $12-14$ & $15-18$ & Above 18 \\
7 & $8-9$ & $10-12$ & $13-15$ & $16-19$ & Above 19 \\
\hline
\end{tabular}

Table 2. Incidence of Intradermal Skin test reactions

Roystonea regia (Kunth.) O.F.Cook. pollen antigen

\begin{tabular}{ccc}
\hline Reactivity & No. & $\mathbf{\%}$ \\
\hline -ve & 547 & 36.47 \\
$1+$ & 219 & 14.6 \\
$2+$ & 453 & 30.2 \\
$3+$ & 194 & 12.93 \\
$4+$ & 87 & 5.8 \\
Total Positivity & 953 & 63.53 \\
Total Significant Positivity & 734 & 48.93 \\
\hline
\end{tabular}

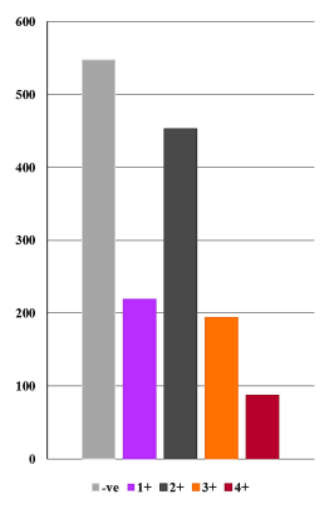

Fig. 01. Incidence of Intradermal Skin test reactions to Roystonea regia (Kunth.) O.F.Cook. pollen antigen

When individual reactions were taken into consideration, highest positivity of $2+$ reactivity was shown by 453 patients $(30.20 \%)$. Among the total positive patients, 219 patients (14.60\%) showed $1+$ reactivity whereas $194(12.93 \%)$ and $87(5.80 \%)$ patients responded with $3+$ and $4+$ reactivity as well.
Over all present investigation recorded an average of $63.53 \%$ of total reactivity among the patients suffering from respiratory ailments. During 1990s two independent studies conducted by Prakashkumar among the people of Kerala recorded a total reactivity of $38.4 \%$ and $38.8 \%$ respectively which is very low when compared with the present results. This also indicate the increased incidence of hypersensitivity during last fifteen years in Kerala. Moreover the absence of non-allergic components in the pollen antigenic extract may be one of the possible reasons for the increased skin test results

In present study, allergic patients, whose hypersensitive activity was studied, hailed from different localities and regions in Kerala. A group of approximately five hundred patients from each locality such as highlands, midlands and coastal belt were selected for the study. Considering the individual pollen antigen reactivity, it was observed that for those pollen types, which are airborne in localities and regions, the reactivity to those patients from the respective region is found to be high.

The aerobiological survey revealed a higher percentage of distribution of the pollen grains of Roystonea regia among the coastal belt of Kerala and similar picture was revealed in the skin test results also. When the total significant reactivity was taken into consideration, patients from coastal belt showed the maximum reactivity $(66.8 \%, \mathrm{n}=$ 334). This show that Roystonea regia pollen cause more allergic problems to people inhabiting coastal belt where its aerial presence was also detected high. These results indicate that the presence of a particular pollen type in a given area has significant influence on the allergic conditions of the patients inhabiting in such localities.

Similar finding was reported by other workers also from different parts of the world. Vobrazkova et al (1986) noticed that allergic reactions are highly influenced by the locality where the patients inhabit. Workers like Paul et al (1975) and Seitz et al (2008) reported that the locality in which the patient inhabits has a significant influence in eliciting allergic manifestations among them. Obtulowicz et al (1996) studied the allergic reactions in two localities namely a polluted urban and unpolluted rural area of Poland. They observed that there is a marked increase in allergic reactions among the people belonging to the urban area, irrespective of their family history of allergic diseases. But in the rural area, the allergic reactions developed only among those patients with a previous history of allergy. It was also stated that a proper analysis of the aerospora of the surrounding environment will be helpful in designing a proper 
immunotherapy schedule for the allergic reactions.

\section{Conclusion}

The present study has proved that the pollen grains of Roystonea regia which are aerially dominant in the atmosphere of Kerala state were potent allergens to the human beings. It is also understood that locality of patient had a high influence on eliciting hypersensitive reactions among human beings. So further investigations are needed to reveal the chemical fractions which make this plant species a potent allergen. This will be useful in future to develop better therapeutic methods for managing hypersensitive reactions caused due to this pollen type.

\section{References}

1. Barkin GD, Mc Grovern J P, Allergy Statistics, Ann Allergy, 1966, 24(1), 602-609.

2. Chai H, Farr RS, Froehlich LA, Mathison DA, Mc Lean JA, Rosenthal RR, Sheffer AL, Spector SL, Townley RG, Standardization of bronchial inhalation challenge procedure, J. Allergy. Clin. Immunol, 1975, 56(4), 323-327.

3. Gopi TV, Prakashkumar R, Ravindran P, Nair, PKK, Comparatative analysis of aerospora of two localities in Kerala, Ind. J. Aerobiol, 1990, 3, 266.

4. Gopi TV, Prakashkumar R, Hazeenabeevi V, Ravindran P, Nair, PKK, Comparatative analysis of the aeroallergens in the midlands of Kerala, J. Palynology, 1992, 28, 11-21.

5. Gravesen S, Fungi as the cause of allergic diseases, Allergy, 1979, 34(3), 135-154.

6. Haahleta TF, Bjorksten M, Heisakala, Suoneimi I, Skin prick test reactivity to common allergens in Finnish adolescence, Allergy, 1980, 35(5), 425-431.

7. Obtulowicz K, Kotlinowska T, Stobiecki M, Dechinik K, Obtulowicz A, Manecki, A, Marszalek M, Schejbal-Chwastek M, Environmental air pollution and pollen allergy, Ann. Agric. Environ. Med, 1996, 3, 131-138.

8. Paul RC, Stanford JL, Misljenovic O, Lefering J, Multiple skin testing of Kenyan school children with a series of new tuberculins, J. Hyg (Lon), 1975, 75(2), 303-13.

9. Prakashkumar R, Studies on allergenicity of airborne pollen of Kerala, Ph. D Thesis, 1992, University of Kerala, Thiruvananthapuram, 1-190.

10. Prakashkumar R, Haeena Beevi VM, Gopi TV, Joshi M, Nair PKK, Raveendran P, Atmospheric pollen and spore spectra of the highlands of Kerala State. Proc. Ist Kerala Sci Cong, 1989, 242-245.

11. Ravindran P, Epidemiology of Asthma with special reference to Kerala. Ind. J. Allergy Appl. Immunol, 1999, 13(1), 7 - 11 .

12. Ravindran P, Joshi MP, Sundaram S Gosh, Gopi TV, Prakashkumar R, Incidence of airborne pollen at Trivandrum during 1986 - 87, Ind. J. Aerobiol, 1988, 1, 71.

13. Ravindran P, Nair, PKK, Joshi MP, Studies in Aerobiology and Human Allergy in Kerala, Indian council Med. Res. New Delhi, 1986.

14. Seitz CS, Brocker EB, Trautmann A, A high school gym-induced disease, Br. J. Sports Med, 2008, 42(12), 998-99.

15. Sheldon JM, Lovell RG, Mathews KP, A manual of Allergy, $2^{\text {nd }}$ Ed. W. B Saunders. Philadalphia, 1967, 507-531.

16. Singh AB, Gangal SV, Subramaniam TAV, Singh $\mathrm{BP}$, Fungal airspora in extramural and intramural environments in New Delhi with reference to allergic disorders-Final Report, The Ministry of Environment and Forests, Government of India, New Delhi. 1994, 127.

17. Viswanathan R, Definition, incidence, aetiology and natural history of asthma, Indian J. Chest Dis, 1964, 6, 109.

18. Vobrazkova E, Kasiakova, Samsinak K, Analysis of dust samples from clinical environment of children with eczemas, Angew. Parasitol, 1986, 27 (1), 53-55.

\section{Cite this article as:}

Sushama Raj R. V. and Prakshkumar R. Allergic evaluation of Roystonea regia (Kunth.) O. F. Cook. among Keralites, India. Annals of Plant Sciences 7.2 (2018) pp. 2063-2066.

do $\mathrm{http}$ // dx.doi.org/10.21746/aps.2018.7.2.13 